\section{Irrigation with thapsigargin and various concentrations of 5-fluorouracil in a sealed-capsule irrigation device in young rabbit eyes to prevent after-cataract}

'St Erik's Eye Hospital, Karolinska Institutet, Stockholm, Sweden

${ }^{2}$ Ullevål University Hospital, University of Oslo, Oslo, Norway

Correspondence: M Kugelberg,

St Erik's Eye Hospital, SE-112 82 Stockholm, Sweden Tel: + 46867230 00; Fax: + 4686510785 . E-mail: maria.kugelberg@ sankterik.se

Received: 24 October 2007 Accepted in revised form: 26 February 2008

Published online: 28 March 2008

Presented at the XXV Congress of the ESCRS on 10 September, 2007, in Stockholm, Sweden.

None of the authors has a proprietary or financial interest in any material, method, or product mentioned.

\begin{abstract}
Aim To investigate the effect on after-cataract and synechiae formation after clear lens extraction and irrigation with different substances in a sealed-capsule irrigation device.

Setting St Erik's Eye Hospital, Stockholm, Sweden.

Methods Clear lens extraction was performed in one eye of 424 -week-old rabbits. The sealed-capsule irrigation device was applied and the sealed system was irrigated for $2 \mathrm{~min}$ with $20 \mathrm{ml}$ of one of four substances: balanced salt solution (BSS), thapsigargin,

5-fluorouracil (5-FU) $50 \mathrm{mg} / \mathrm{ml}$, or 5 -FU 25 $\mathrm{mg} / \mathrm{ml}$. The substance then was washed out for $10 \mathrm{~s}$ with BSS. The eyes were left aphakic. Formation of after-cataract and synechiae was evaluated during two clinical examinations 3.5 and 5.5 weeks postoperatively, by photographs 5 weeks postoperatively, and by histologic evaluation of haematoxylin-eosin-stained slides after the 6-week end point postoperatively. After-cataract and synechiae were graded on a scale from 0 to 4 . KruskalWallis analysis of variance with multiple comparisons was used for statistical analyses. Results $\quad 5-\mathrm{FU} 50 \mathrm{mg} / \mathrm{ml}$ prevented aftercataract and synechiae formation best when compared with all other substances at all evaluations. 5 -FU $25 \mathrm{mg} / \mathrm{ml}$ was not as effective, and thapsigargin was ineffective in this animal model.
\end{abstract}

MT Abdelwahab', M Kugelberg ${ }^{1}$ and C Zetterström²
Conclusion 5-FU $50 \mathrm{mg} / \mathrm{ml}$ used in the sealedcapsule irrigation device satisfactorily prevents after-cataract and synechiae. Thapsigargin was ineffective in this animal model.

Eye (2008) 22, 1508-1513; doi:10.1038/eye.2008.92; published online 28 March 2008

Keywords: sealed-capsule irrigation; perfect capsule; fluorouracil; thapsigargin; paediatric cataract surgery; posterior capsule opacification

\section{Introduction}

Posterior capsule opacification (PCO) is a common complication after cataract surgery. ${ }^{1}$ In children, the younger the child, the more extensive is the after-cataract that develops ${ }^{2}$ and a posterior capsulorhexis ${ }^{3}$ and anterior vitrectomy also can help reducing the amount. ${ }^{4-7}$ However, in the smallest children, an anterior vitrectomy is not always sufficient, but visual axis opacification (VAO) may develop and require a secondary procedure to remove the lens epithelial cells (LECs) on the back of the optic and in the residual vitreous. ${ }^{8,9}$ A new sealed-capsule irrigation device, that is, Perfect Capsule (Milvella, Ltd, Epping, Australia), ${ }^{10}$ might be helpful to prevent VAO in children. The capsule is left intact, the Perfect Capsule is sealed to the capsule with a vacuum, and the system can be flushed with a substance to 
remove all the LECs. Initially, it was believed that distilled deionized water would remove the LECs through osmotic lysis. However, a recent study of human adults found that irrigation with distilled deionized water had no effect on PCO. ${ }^{11}$

We previously found that 5-fluorouracil (5-FU) $50 \mathrm{mg} / \mathrm{ml}$ effectively killed LECs in a rabbit model. ${ }^{12}$ We also showed that it is safe to use 5-FU with the device. ${ }^{13}$ However, since 5-FU is an antimetabolite and potentially toxic, it is crucial to identify the lowest concentration at which 5-FU is effective. We also evaluated thapsigargin, a hydrophobic inhibitor of endoplasmic reticulum $\left(\mathrm{Ca}^{2+}\right)$-ATPase, which has proved effective in in vitro studies of human lens capsules. ${ }^{14,15}$

This study was conducted to compare balanced salt solution (BSS), 5 -FU $50 \mathrm{mg} / \mathrm{ml}, 5-\mathrm{FU} 25 \mathrm{mg} / \mathrm{ml}$, and thapsigargin in a sealed-capsule irrigation device to determine the substance that is most effective in preventing after-cataract formation and postoperative inflammation.

\section{Materials and methods}

\section{Animals}

Forty-two New Zealand white rabbits, 4 weeks old (average weight, $302 \mathrm{~g}$ ), underwent unilateral clear lens extraction. The experiment was approved by the Northern Stockholm Animal Experiments Ethics Committee and adhered to the Association for Research in Vision and Ophthalmology statement on the Use of Animals in Ophthalmic and Vision Research.

\section{Surgery}

Before surgery, the pupils were fully dilated with a mixture of cyclopentolate $0.75 \%$ and phenylephrine $2.5 \%$. The surgeries were performed by one experienced anterior segment surgeon (CZ). The animals were deeply anaesthetized with a mixture of ketamine hydrochloride and Xylocaine chloride. Topical anaesthesia (tetracaine chloride eye drops) was applied to each eye. A 2.8-mm corneal incision was created with a disposable bevel-up 45-degree slit knife. Healon GV (Advanced Medical Optics) was injected into the anterior chamber followed by creation of a tear-resistant capsulorhexis of about $3 \mathrm{~mm}$. The capsulorhexis had to be less than $4-4.5 \mathrm{~mm}$ to allow the Perfect Capsule to fit and seal tightly because the inner diameter is $5 \mathrm{~mm}$, and the rhexis has to be fully covered by the device to obtain a vacuum and remained sealed throughout the procedure. Irrigation/aspiration of the lens material was carried out using BSS with heparin $10000 \mathrm{IU} / 1$.

The Perfect Capsule was folded with forceps and inserted through the small incision, pushed down onto the anterior capsule, and a vacuum syringe was pulled back and locked to create the vacuum, holding the device in place during irrigation. The sealed system with the capsule then was irrigated with one of four substances for $2 \mathrm{~min}$, followed by $10 \mathrm{~s}$ of BSS flush to wash out the residual substance.

After irrigation was completed, the vacuum was released and the Perfect Capsule was removed. The corneal incision was closed using a continuous 10-0 nylon suture. One milligram of cefuroxime was injected intracamerally. Starting from the day after surgery, the rabbits received dexamethasone eye drops $1 \mathrm{mg} / \mathrm{ml}$ four times daily in the operated eye, the dose of which was later tapered to twice daily during the last 2 weeks.

\section{Study design}

Ten eyes in group 1 were irrigated with BSS, 11 eyes in group 2 were irrigated with thapsigargin $300 \mu \mathrm{M}$ (Sigma), 10 eyes in group 3 were irrigated with $5-\mathrm{FU} 50 \mathrm{mg} / \mathrm{ml}$, and 11 eyes in group 4 were irrigated with 5-FU $25 \mathrm{mg} / \mathrm{ml}$. During the 2-min irrigation period, about $20 \mathrm{ml}$ of each substance was washed through the system.

To evaluate the effects of irrigation with different 5-FU concentrations and thapsigargin on after-cataract, we evaluated after-cataract and synechiae formation during two clinical examinations 3.5 and 5.5 weeks

postoperatively, retroillumination photographs that were obtained 5 weeks postoperatively, and histologic evaluation. In these eyes, it was not possible to perform any digital evaluation of $\mathrm{PCO}$, as the posterior synechia often was extensive, and no red reflex then was obtained. We therefore had to subjectively grade the after-cataract. Measurements and examinations were performed through fully dilated pupils (with a mixture of cyclopentolate $0.75 \%$ and phenylephrine $2.5 \%$ ) and in a masked manner, that is, the examiner did not know which solution had been used in the eye. After-cataract and synechiae were graded on a scale from 0 to 4 , where 0 indicated no after-cataract or a totally round large pupil, 1 indicated minimal after-cataract or some peripheral posterior synechiae, 2 indicated medium after-cataract or a pupil not totally attached by synechiae but about half of the pupil. Three indicated moderate after-cataract or a pupil almost covered by posterior synechiae and 4 indicated extensive after-cataract and a pupil totally covered by posterior synechiae.

All animals were killed 6 weeks after surgery. All but two eyes in each group were extracted and fixated in formalin for histologic evaluation. Two eyes in each group were fixed for later transmission electron microscopy evaluation of the posterior capsule not described here. The eyes fixated in formalin were sectioned, mounted, and stained with haematoxylin and 
eosin and analysed for after-cataract; however, it was not possible to evaluate posterior synechiae histologically.

\section{Statistical analysis}

Kruskal-Wallis analysis of variance with multiple comparisons was used to calculate the difference between the groups regarding the formation of after-cataract and synechiae.

\section{Results}

The detailed results of after-cataract and synechiae formation are shown in Tables 1 and 2. Thapsigargin (Figure 1) was ineffective in preventing LEC proliferation in young rabbits, and the substance was not associated with less after-cataract ( $P>0.05$ in all four evaluations) or synechiae $(P>0.05$ in all three evaluations) than BSS (Figure 2). Irrigation with 5-FU $50 \mathrm{mg} / \mathrm{ml}$ (Figure 3) resulted in less after-cataract $(P<0.01$ in all four evaluations) and synechiae $(P<0.001$ in all three evaluations) than BSS. Irrigation with $5-\mathrm{FU} 25 \mathrm{mg} / \mathrm{ml}$ (Figure 4) resulted in less after-cataract than BSS at the first clinical examination and at the photographic and histologic evaluations $(P<0.05)$ but not at the second clinical examination $(P>0.05)$. 5-FU $25 \mathrm{mg} / \mathrm{ml}$ also was associated with less synechiae than BSS in all three evaluations $(P<0.05)$.

\section{Discussion}

Our data showed that 5 -FU $50 \mathrm{mg} / \mathrm{ml}$ seems to be the most-effective substance of all the substances tested for preventing after-cataract and synechiae formation in this animal model. 5-FU $50 \mathrm{mg} / \mathrm{ml}$ was the most-effective agent in all four evaluations. In the current study, we wanted to determine if it was possible to lower the 5-FU concentration; however, at least in the young rabbit, a concentration of $50 \mathrm{mg} / \mathrm{ml}$ is needed.

In a recent study, 5-FU at a low concentration of $12.5 \mathrm{mg} / \mathrm{ml}$ was administered during hydrodissection in the rabbit eye, and no inhibitory effect of LEC proliferation was seen. ${ }^{16}$ In another study, ${ }^{17}$ clear lens extraction was performed in rabbit eyes followed by injection of a drug mixed with an ophthalmic viscosurgical device (OVD) in the capsular bag. In two rabbits, the investigators injected $5-\mathrm{FU} 33 \mathrm{mg} / \mathrm{ml}$ mixed in the OVD in the bag, left the OVD in the capsular bag for $3 \mathrm{~min}$, then rinsed it out. The concentration, however, was probably lower when the drug is mixed with OVD, and there was no irrigation, but merely contact with the mixed OVD for $3 \mathrm{~min}$. In this study, 5-FU did not effectively prevent PCO. A high concentration of 5-FU seems to achieve the inhibitory effect in vivo in the rabbit eye. Also, our study differs from the above-mentioned studies, in that, as the capsule was empty and exposed only to pure 5-FU when using the Perfect Capsule, and the LECs should therefore be more sensitive. Even so, in our model, a concentration of $50 \mathrm{mg} / \mathrm{ml}$ was needed.

Thapsigargin was ineffective in preventing LEC proliferation and migration in this young rabbit model; however, it has earlier reported to be effective in killing human LECs. ${ }^{14,15}$ Coating polymethylmethacrylate lenses with thapsigargin effectively prevented LEC proliferation in an in vitro study of human capsular bags. ${ }^{14}$ In an extensive study of rabbit and human

Table 1 Comparison of after-cataract formation at four different evaluations

\begin{tabular}{lccc}
\hline After-cataract & \multicolumn{2}{c}{ P-values compared to BSS } \\
\cline { 2 - 4 } & 5 -FU $50 \mathrm{mg} / \mathrm{ml}$ & 5 -FU 25 mg/ml & Thapsigargin 300 $\mu \mathrm{M}$ \\
\hline Clinical examination 1 & 0.00015 & 0.0039 & 0.76 \\
Clinical examination 2 & 0.0073 & 0.15 & 1.0 \\
Photographic evaluation & 0.00072 & 0.0062 & 1.0 \\
Histologic evaluation & 0.0022 & 0.037 & 0.19 \\
\hline
\end{tabular}

Table 2 Comparison of synechiae formation at three different evaluations

\begin{tabular}{lccr}
\hline Synechiae & \multicolumn{2}{c}{ P-values compared to BSS } \\
\cline { 2 - 4 } & 5-FU 50 mg/ml & 5-FU 25 mg/ml & Thapsigargin 300 $\mu$ M \\
\hline Clinical examination 1 & 0.00017 & 0.0072 & 1.0 \\
Clinical examination 2 & 0.00028 & 0.012 & 1.0 \\
Photographic evaluation & 0.000006 & 0.00044 & 0.80 \\
\hline
\end{tabular}



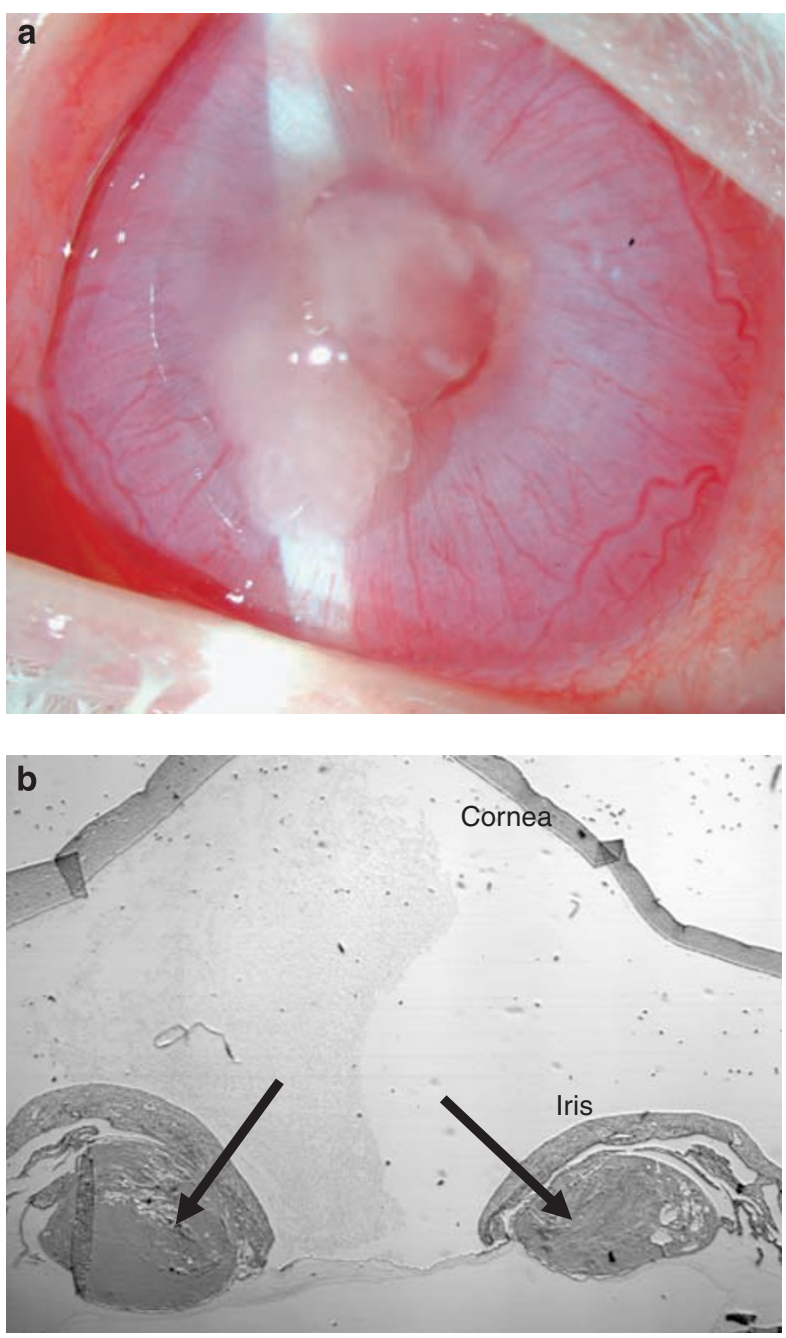

Figure 1 (a) Slit-lamp retroillumination photograph of an eye irrigated with thapsigargin. After-cataract is seen also in the anterior chamber, and the pupil is small with synechiae attached. (b) Histologic slide (a $\times 4$ magnification objective was used) shows an eye irrigated with thapsigargin. The arrows indicate Sommering's ring.

capsular bags in vitro, Duncan et al ${ }^{15}$ found that LEC growth in rabbit capsular bags exposed to thapsigargin was not inhibited by the substance; however, in bags exposed to $5-\mathrm{FU} 25 \mathrm{mg} / \mathrm{ml}$, LEC growth was totally inhibited. When performing the same experiment in human donor capsular bags, thapsigargin totally inhibited cell proliferation, and 5-FU $25 \mathrm{mg} / \mathrm{ml}$ almost totally inhibited proliferation, although some live cells were seen after 28 days in the outer region of the human capsular bags. Duncan et $\mathrm{al}^{14}$ also performed cell cultures of human LECs (FHL124 cells), in which the cells were exposed to different substances for $2 \mathrm{~min}$. In cell culture, thapsigargin and 5-FU $25 \mathrm{mg} / \mathrm{ml}$ effectively killed the cells. The explanation for why thapsigargin is more effective in human LECs than in rabbit LECs is unknown;
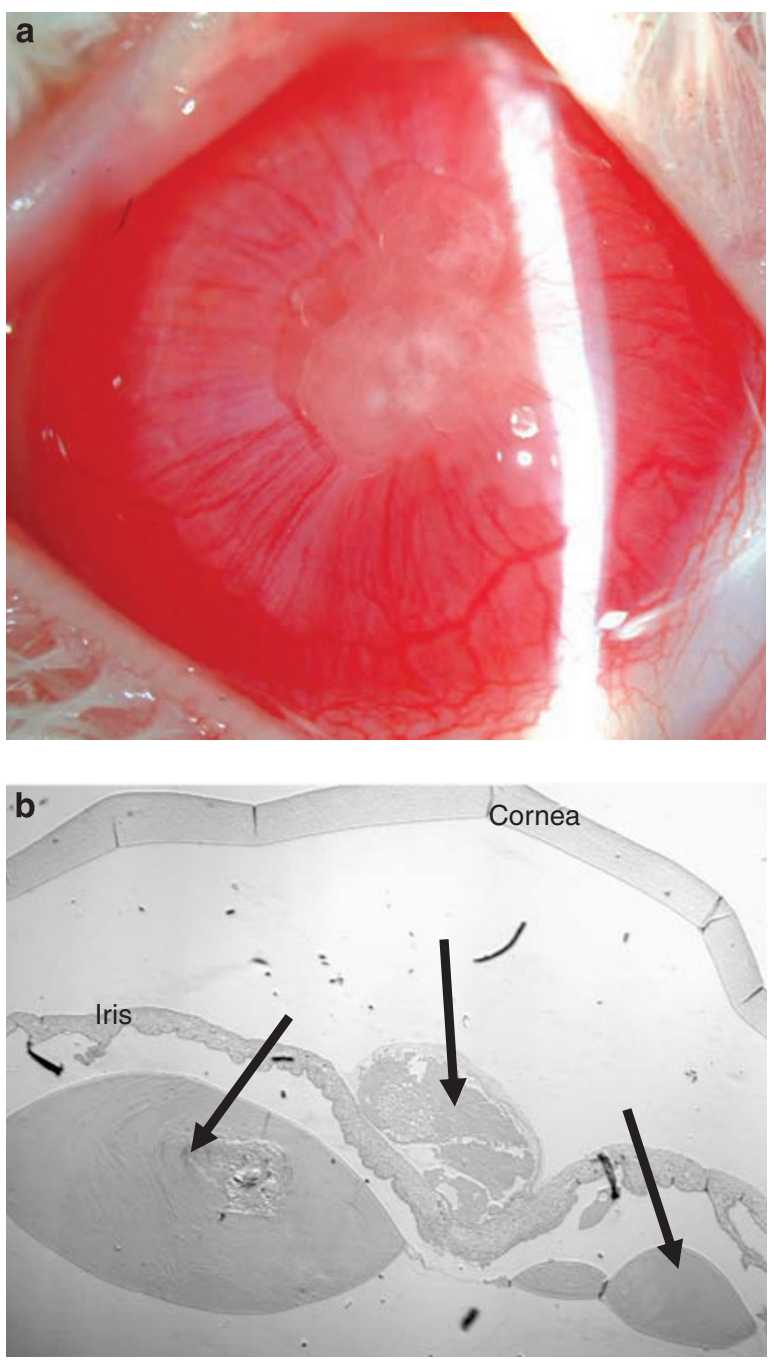

Figure 2 (a) Slit-lamp retroillumination photograph of an eye irrigated with BSS. After-cataract is seen also in the anterior chamber, and the pupil is small with synechiae attached. (b) Histologic slide (a $\times 4$ magnification objective was used) shows an eye irrigated with BSS. The arrows indicate Sommering's ring and after-cataract in the anterior chamber.

however, Duncan $e t a l^{14}$ proposed that the rabbit model often uses young animals whereas the human donor eyes most often are older. The rabbit cells are, therefore, more sensitive to stress than the human cells. In addition, rabbit cells divide faster than aged human cells and 5-FU mainly targets rapidly dividing cells. We focused primarily on the use of the Perfect Capsule in children's eyes. They also have very rapidly dividing cells, which is why they develop more extensive after-cataract compared to adults. Therefore, 5-FU might be a good substance to use in paediatric eyes. Thapsigargin might be more promising in adult eyes, in which the use of the Perfect Capsule is mostly indicated in cases in which a posterior capsulotomy cannot be performed, such as in 

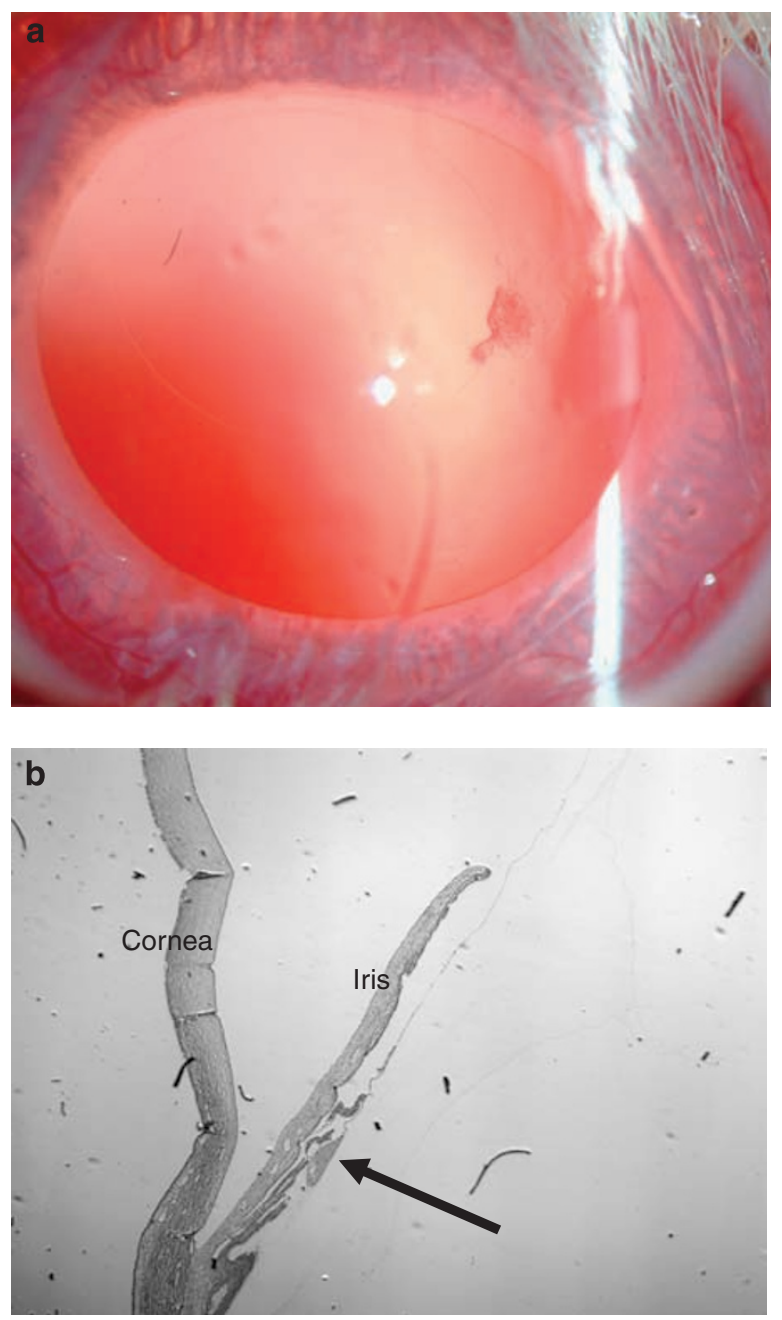

Figure 3 (a) Slit-lamp retroillumination photograph of an eye irrigated with 5 -FU $50 \mathrm{mg} / \mathrm{ml}$. Almost no after-cataract is seen and the pupil does not have synechiae but is round and well dilated. (b) Histologic slide ( $\times 4$ magnification objective was used) shows an eye irrigated with 5 -FU $50 \mathrm{mg} / \mathrm{ml}$. The arrow indicates minute after-cataract at the equator of the capsular bag.

patients with accommodative intraocular lenses of different material.

When using the Perfect Capsule, the system is supposed to be sealed all the time; however, the vacuum can be incomplete and hypothetically a substance can escape into the anterior chamber. We showed previously that 5 -FU $50 \mathrm{mg} / \mathrm{ml}$ is non-toxic to the adjacent intraocular structures. ${ }^{13}$ When 5-FU was injected in the bag after clear lens extraction without using the Perfect Capsule, other ocular tissues such as the corneal endothelial cells, trabecular meshwork, and retina were intact. Even when 5-FU was left in the capsular bag after irrigation and not washed out with BSS, the other tissues were unaffected. 5-FU is often used in glaucoma surgery and also in paediatric cases. ${ }^{18,19} 5$-FU also has been used
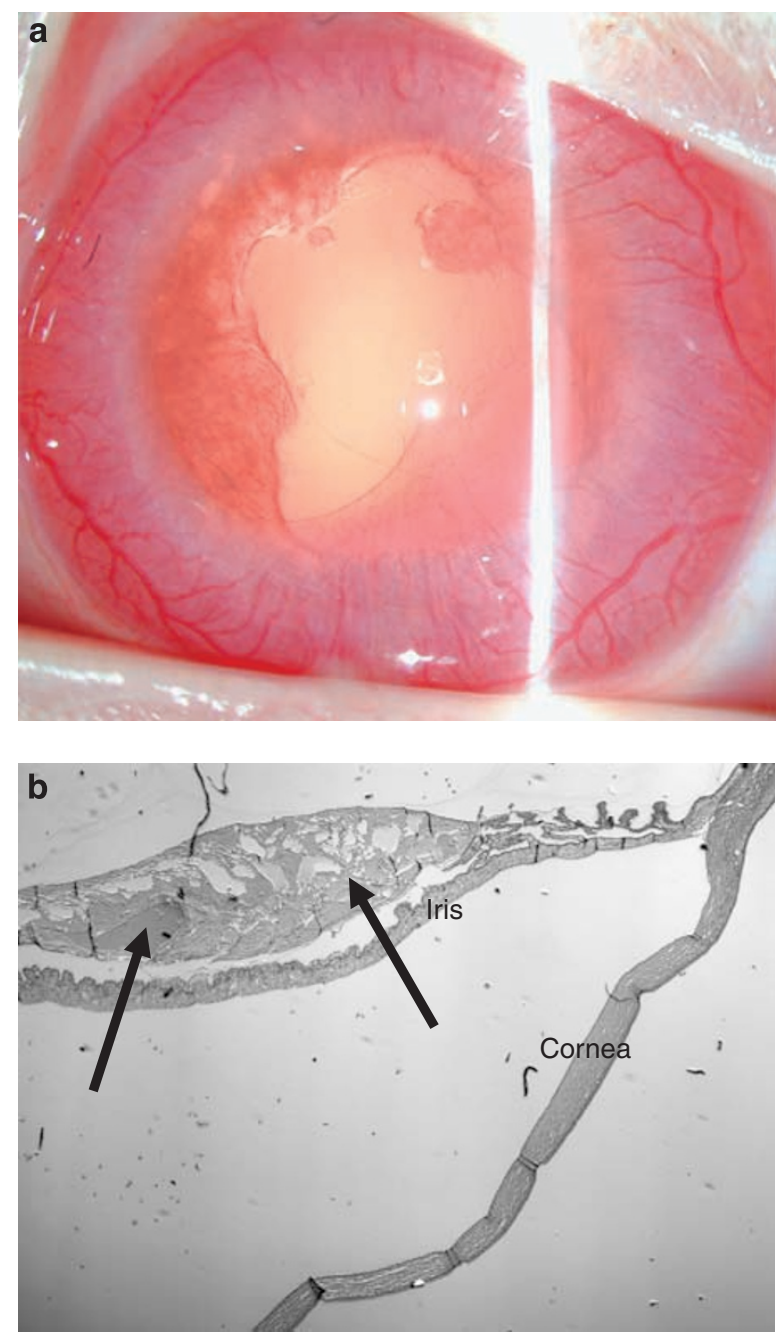

Figure 4 (a) Slit-lamp retroillumination photograph of an eye irrigated with $5-\mathrm{FU} 25 \mathrm{mg} / \mathrm{ml}$. Some after-cataract is seen in the periphery and the pupil has some synechiae. (b) Histologic slide (a $\times 4$ magnification objective was used) shows an eye irrigated with $5-\mathrm{FU} 25 \mathrm{mg} / \mathrm{ml}$. The arrows indicate after-cataract centrally.

intravitreally to manage retinal detachments..$^{20,21}$ Furthermore, it has been shown that intraocular use of 5-FU is safer for the corneal endothelium than mitomycin C.22

In the current study, irrigation with the substances lasted for $2 \mathrm{~min}$. In our earlier studies, irrigation was continued for $5 \mathrm{~min}$. As the rabbit model is not fully representative of the human eye, studies in humans are needed to determine the length of the irrigation time that prevents development of after-cataract in children.

One limitation of the current study is that the surgeon is not masked to the solution used. This can of course create bias. Another limitation of the study is that the grading of the after-cataract is subjective, but in our model, this is difficult to get around. The rabbits were kept aphakic in our study, although implantation of 
intraocular lenses has become more common in paediatric cataract surgery also. If an intraocular lens is implanted, less after-cataract and synechiae develop ${ }^{23}$ and it is then more difficult to see the difference between the groups, which is why we chose to leave the eyes aphakic.

In conclusion, the current study showed that in this young rabbit model, a concentration of $50 \mathrm{mg} / \mathrm{ml}$ is needed for 5-FU to prevent formation of after-cataract and synechiae. Thapsigargin was ineffective in this model.

\section{Acknowledgements}

Financial support was provided by a regional agreement on medical training and clinical research (ALF) between the Stockholm county council and the Karolinska Institute. The study also was supported in part by Stiftelsen Synfrämjandets Forskningsfond, the Jerring Foundation, Stiftelsen Kronprinsessan Margaretas Arbetsnämnd för Synskadade, Milvella Limited, and Sigvard \& Marianne Bernadottes Forskningsstiftelse för Barnögonvård, Sweden.

\section{References}

1 Hayashi K, Hayashi H. Posterior capsule opacification in the presence of an intraocular lens with a sharp versus rounded optic edge. Ophthalmology 2005; 112: 1550-1556.

2 Zetterstrom C, Lundvall A, Kugelberg M. Cataracts in children. J Cataract Refract Surg 2005; 31: 824-840.

3 Vasavada AR, Nihalani BR. Pediatric cataract surgery. Curr Opin Ophthalmol 2006; 17: 54-61.

4 Cakmak SS, Caca I, Unlu MK, Cakmak A, Olmez G, Sakalar YB. Surgical technique and postoperative complications in congenital cataract surgery. Med Sci Monit 2006; 12: CR31-CR35.

5 Kugelberg M, Kugelberg U, Bobrova N, Tronina S, Zetterstrom C. After-cataract in children having cataract surgery with or without anterior vitrectomy implanted with a single-piece AcrySof IOL. J Cataract Refract Surg 2005; 31: 757-762.

6 Kugelberg M, Zetterstrom C. Pediatric cataract surgery with or without anterior vitrectomy. J Cataract Refract Surg 2002; 28: 1770-1773.

7 Zetterstrom C, Kugelberg M. Paediatric cataract surgery. Acta Ophthalmol Scand 2007; 85: 698-710.

8 Kugelberg M, Kugelberg U, Bobrova N, Tronina S, Zetterstrom C. Implantation of single-piece foldable acrylic IOLs in small children in the Ukraine. Acta Ophthalmol Scand 2006; 84: 380-383.

9 Vasavada AR, Trivedi RH, Nath VC. Visual axis opacification after AcrySof intraocular lens implantation in children. J Cataract Refract Surg 2004; 30: 1073-1081.
10 Maloof AJ, Pandey SK, Neilson G, Milverton EJ. Selective death of lens epithelial cells using demineralized water and Triton X-100 with PerfectCapsule sealed capsule irrigation: a histological study in rabbit eyes. Arch Ophthalmol 2005; 123: 1378-1384.

11 Rabsilber TM, Limberger IJ, Reuland AJ, Holzer MP, Auffarth GU. Long-term results of sealed capsule irrigation using distilled water to prevent posterior capsule opacification: a prospective clinical randomised trial. $\mathrm{Br} J$ Ophthalmol 2007; 91: 912-915.

12 Abdelwahab MT, Kugelberg M, Kugelberg U, Zetterstrom C. After-cataract evaluation after using balanced salt solution, distilled deionized water, and 5-fluorouracil with a sealed-capsule irrigation device in the eyes of 4-week-old rabbits. J Cataract Refract Surg 2006; 32: 1955-1960.

13 Abdelwahab MT, Kugelberg M, Seregard S, Zetterstrom C. Safety of irrigation with 5-fluorouracil in a sealed-capsule irrigation device in the rabbit eye. J Cataract Refract Surg 2007; 33: 1619-1623.

14 Duncan G, Wormstone IM, Liu CS, Marcantonio JM, Davies PD. Thapsigargin-coated intraocular lenses inhibit human lens cell growth. Nat Med 1997; 3: 1026-1028.

15 Duncan G, Wang L, Neilson GJ, Wormstone IM. Lens cell survival after exposure to stress in the closed capsular bag. Invest Ophthalmol Vis Sci 2007; 48: 2701-2707.

16 Chew J, Werner L, Stevens S, Hunter B, Mamalis N. Evaluation of the effects of hydrodissection with antimitotics using a rabbit model of Soemmering's ring formation. Clin Experiment Ophthalmol 2006; 34: 449-456.

17 Fernandez V, Fragoso MA, Billotte C, Lamar P, Orozco MA, Dubovy $S$ et al. Efficacy of various drugs in the prevention of posterior capsule opacification: experimental study of rabbit eyes. J Cataract Refract Surg 2004; 30: 2598-2605.

18 Ehrlich R, Snir M, Lusky M, Weinberger D, Friling R, Gaton DD. Augmented trabeculectomy in paediatric glaucoma. Br J Ophthalmol 2005; 89: 165-168.

19 Membrey WL, Bunce C, Poinoosawmy DP, Fitzke FW, Hitchings RA. Glaucoma surgery with or without adjunctive antiproliferatives in normal tension glaucoma: 2 Visual field progression. Br J Ophthalmol 2001; 85: 696-701.

20 Blumenkranz M, Hernandez E, Ophir A, Norton EW. 5-fluorouracil: new applications in complicated retinal detachment for an established antimetabolite. Ophthalmology 1984; 91: 122-130.

21 Wickham L, Bunce C, Wong D, McGurn D, Charteris DG Randomized controlled trial of combined 5-Fluorouracil and low-molecular-weight heparin in the management of unselected rhegmatogenous retinal detachments undergoing primary vitrectomy. Ophthalmology 2007; 114: 698-704.

22 Nuyts RM, Pels E, Greve EL. The effects of 5-fluorouracil and mitomycin $\mathrm{C}$ on the corneal endothelium. Curr Eye Res 1992; 11: 565-570.

23 Zetterstrom C, Kugelberg U, Lundgren B, Syren-Nordqvist S. After-cataract formation in newborn rabbits implanted with intraocular lenses. J Cataract Refract Surg 1996; 22: $85-88$ 